\title{
LA MEMORIA IMPEDIDA EN PAUL RICOEUR*
}

\author{
Lythgoe Esteban** \\ estebanlythgoe@yahoo.com.ar
}

RESUMEN El objetivo del presente artículo será sostener que la memoria impedida, carente de una dimensión simbólica y 'sustraída del tiempo', tratada en "La memoria, la historia, el olvido" plantea un límite originalmente no contemplado a la solución narrativa de la aporía del tiempo presentada en "Tiempo y narración". Sin embargo, observamos varios elementos que llevan a desdibujar la diferencia entre la memoria impedida y la manipulada. Nuestra hipótesis es que el recurso a la metapsicología freudiana, y especificamente, su concepto de trabajo, le impiden a Ricoeur desarrollar cabalmente este límite. Recurriremos a las tesis de Certeau acerca de la escritura histórica como gesto sepultural, para ahondar en este límite y determinar las vías para superarlo.

Palabras clave Símbolo, ideología, trabajo, duelo, rememoración.

ABSTRACT The objective of this paper is to argue that an impeded memory, devoid of a symbolic dimension and "subtracted from time", treated in "Memory, History, Forgetting" poses a limit not originally contemplated in the narrative solution of the aporia of time, as presented in "Time and Narrative". However, we find several elements that lead to blur the difference between impeded and manipulated memory. Our hypothesis is that by resourcing to Freudian metapsychology, and specifically its concept of work, prevents Ricoeur from fully developing this limit. We turn to Certeau's theses about

* Artículo sometido el 25/10/2017. Acepto el 12/12/2017.

** Fundación UADE/Conicet Facultad de Ciencias Jurídicas y Sociales, Ciudad Autónoma de Buenos Aires, Buenos Aires, Argentina. 
historical writing as a sepulture gesture, to develop this limit and determine the ways to overcome it.

Keywords Symbol, ideology, work, mourning, remembrance.

\section{Los límites a la tematización del tiempo}

"Tiempo y narración" es, sin lugar a dudas, una de las obras más importantes de Paul Ricoeur. En sus tres extensos volúmenes, propone un acercamiento hermenéutico a una gran variedad de temáticas que van desde la estética de la recepción a la epistemología de la historia. Sin embargo, como incluso su título lo plantea, esta obra es fundamentalmente acerca del tiempo. El tiempo es presentado, a la vez, como un factum y una imposibilidad. Un factum, porque el ser humano es un ser-en-el-tiempo, donde el '[...] 'en' expresa la precedencia misma del tiempo respecto del pensamiento que ambiciona circunscribir su sentido, por tanto desarrollarlo." (Ricoeur, 1996a, p. 1018). Sin embargo, también es caracterizado como una imposibilidad, en la medida en que no es posible representárselo o pensarlo directamente. Ante la imposibilidad de la filosofía especulativa de tematizar directamente al tiempo, Ricoeur propone como alternativa un abordaje "poético" (cf. Ricoeur 1996a, p. 636). La hipótesis de base de esta obra será, pues, que "[...] el tiempo se hace humano cuando se articula de modo narrativo; a su vez, la narración es significativa en la medida en que describe los rasgos de la experiencia temporal." (Ricoeur, 1995a, p. 39). Dicho de otra manera, tiempo y lenguaje no son lo mismo, pero, en lo que respecta al tiempo, si queremos saber qué es el tiempo, debemos hacer un rodeo por la narración para volverla concebible. ${ }^{1}$

Las aporías del tiempo, ligadas, fundamentalmente a la tensión entre el tiempo vivido y el tiempo cósmico, son resueltas poéticamente, por lo que su solución no es absoluta, sino que posee límites asociados a la narración como tal. ${ }^{2}$ En "Tiempo y narración”, Ricoeur distingue dos tipos de límites diferentes, uno interno y otro externo a esta capacidad: “[...] por límite interno se entenderá el traspasar, hasta el agotamiento del arte de narrar, casi el umbral de lo inescrutable. Por límite externo, la superación del género narrativo por otros géneros de discurso, que, a su manera, se dedican también a decir del

1 Sobre una mayor precisión acerca de la correlación entre narración y tiempo, y hasta dónde esta correlación se puede considerar una constante transcultural o un vínculo propio de la cultura occidental moderna, conferir Vergara (2004, pp. 148-149) y Greisch (2001, pp. 180-185).

2 Cf. Vergara (2004, p. 74). 
tiempo" (Ricoeur, 1996a, p. 1032). El límite interno remite a aquellas obras de ficción, como las tratadas en el tomo II de "Tiempo y narración" ("La señora Dalloway", "La montaña mágica" y "El tiempo recobrado"), que operan sobre el orden del tiempo cotidiano haciendo que éste termine siendo sobrepasado por la eternidad. El límite externo en la refiguración del tiempo, por su parte, se encuentra ligado a todos aquellos modos escriturales diferentes a la narración que también intentan resolver las aporías temporales, como es el caso de la Biblia hebrea o la poesía épica, dramática y lírica.

Existe, sin embargo, un límite que no fue contemplado en "Tiempo y narración", y es el de la carencia absoluta de toda mediación simbólica a la realidad. Esta cuestión ha estado inicialmente ligada con la reflexión acerca del testimonio de los sobrevivientes del Holocausto. ${ }^{3}$ Primo Levi describe claramente este límite, al explicar que aquellos que relatan lo sucedido en el Holocausto no son quienes han vivido el acontecimiento al límite, no son los testigos integrales. Aquellos que lo han vivido al límite son quienes o no han vuelto a contarlo o quienes han perdido la capacidad de narrarlo, se han vuelto mudos. Estos últimos son los que en los campos de concentración fueron denominados los "musulmanes". ${ }^{4}$ En filosofía de la historia, la afirmación de Saul Friedlander acerca de los límites de la representación del discurso histórico, ${ }^{5}$ dio lugar a un extenso debate en el que Ricoeur no quedó fuera. El filósofo reconoce que la afirmación plantea un límite interno, ligado al agotamiento de las formas de representación de nuestra cultura para hacer visible a la solución final, y otro externo, que es la necesidad de que este acontecimiento sea dicho. ${ }^{6}$ En esta obra, Ricoeur reconoce el agotamiento de las formas narrativas heredadas del siglo XIX para referirse al Holocausto, así como la necesidad de explorar modos alternativos de exploración. ${ }^{7}$ Esta observación es consistente con el límite externo de la narración para resolver las aporías del tiempo planteado en “Tiempo y narración". Sin embargo, el autor considera que el Holocausto no constituye un límite externo a la representación, "[...] si se considera la verdadera

3 Las dos cuestiones más significativas que Ricoeur considera imposibles de abordar directamente y que, por lo tanto, deben ser mediadas simbólicamente son el problema del mal y el del tiempo. Consideramos que el Holocausto se caracteriza por ser un caso paradigmático sobre ambos temas. Aunque el presente artículo se refiere específicamente al tiempo, cabe destacar que en el epílogo a "La memoria, la historia, el olvido", el Holocausto también será asociado a la cuestión del mal (cf. Ricoeur, 2004a, p. 592).

4 Cf. Levi, 1989, pp. 72-73.

5 Cf. Friedlander, 2007, p. 27: "De modo que, por un lado, nuestras tradicionales categorías de conceptualización y representación bien pueden ser insuficientes, y nuestro lenguaje mismo bien puede ser problemático. Y por otro lado, frente a estos sucesos sentimos la necesidad de contar con algún relato estable; un campo infinito de discursos posibles plantea la cuestión de los límites con marcada severidad."

6 Cf. Ricoeur, 2004a, p. 333.

7 Cf. Ricoeur, 2004a, p. 341. 
naturaleza de la relación de la historia con la memoria, que es una reasunción crítica [...]" (Ricoeur, 2004a). Con otras palabras, la representación histórica termina asentándose en la problemática mnémica, por lo que, consecuentemente, el problema del límite absoluto de mediación simbólica termina desplazándose de la historia a la memoria.

El objetivo de las siguientes páginas consiste, pues, en reconstruir este límite a través del análisis de los usos y abusos de la memoria. Utilizando como hilo conductor el concepto de símbolo, contrapondremos la presencia de este concepto en la memoria manipulada con su ausencia en el análisis de la memoria impedida. De esta contraposición surgirá la hipótesis de que esta ausencia no es debida a que Ricoeur no utiliza más esta categoría en sus análisis, tal como lo insinúa Barash, sino a que "la memora impedida se caracteriza por carecer de toda mediación simbólica". Tal como se desprende de los análisis de "Tiempo y narración", esta carencia tiene efectos a nivel temporal, consistentes con la descripción de la repetición realizada por Freud. Sostendremos, sin embargo, aunque Ricoeur presente dicha posibilidad, no puede desarrollarla, obstaculizado fundamentalmente por su recepción de la metapsicología freudiana.

\section{Símbolo y tiempo}

En su obra "Collective Memory \& the Historical Past", Jeffrey Barash destaca el modo que Ricoeur fue progresivamente dando mayor alcance al concepto de símbolo, a medida que su hermenéutica se ampliaba. ${ }^{8}$ En su descripción señala que, tanto en "La simbólica del mal" como en su ensayo sobre Freud, Ricoeur contrapuso una concepción del símbolo, que "[...] designa el común denominador de todas las maneras de objetivar, de dar sentido a la realidad" (Ricoeur, 1990, p. 13) y otra, que es la expresión lingüística de un doble sentido, que debe ser interpretado. En su obra sobre Freud, Ricoeur consideró que el sentido más acotado le resultaba más útil para la labor de la hermenéutica. Quince años más tarde, en el primer tomo de Tiempo y narración, volvió a la doble definición del símbolo, aunque en este caso inclinándose el sentido amplio. En la Mimesis I, Ricoeur describe a la precomprensión del mundo de la acción sobre la que se funda la trama. Ésta consta de tres rasgos, los estructurales, los temporales y los simbólicos. Al referirse a las mediaciones simbólicas explica que 
entre una acepción demasiado pobre y otra demasiado rica, he optado personalmente por un uso cercano al de Cassirer en su Philosophie des formes symboliques, en la medida en que, para éste, las formas simbólicas son procesos culturales que articulan toda la experiencia (Ricoeur, 1995, p. 120).

Dada la relevancia y amplitud que va adquiriendo el concepto del símbolo en el transcurso de la obra de Ricoeur, Barash concluye su resumen manifestando su desconcierto al observar que ni en los dos tomos subsiguientes de "Tiempo y narración" ni en sus dos grandes obras posteriores, Sí mismo como otro y La memoria, la historia, el olvido se lo vuelve a tratar. Así explica,

Sea como fuera, Paul Ricoeur, luego de una precipitada referencia al tema del símbolo al comienzo de Tiempo y narración, no clarifica más extensamente el tema en los dos volúmenes de esta obra que siguieron, tampoco volvió a él en sus principales obras posteriores como Sí mismo como otro (Soi-même comme un autre, 1990) o La memoria, la historia, el olvido (La mémoire, l'histoire, l'oubli, 2000). En vista del rol central acordado al tópico de la experiencia colectiva y la memoria colectiva en La memoria, la historia, el olvido, esta ausencia del análisis del símbolo es desconcertante; pues, como lo interpreto, sólo una teoría adecuada del símbolo puede dar cuenta de los complejos niveles de mediación que yacen entre la experiencia personal y la memoria en la esfera colectiva (Barash, 2017, p. 73).

Coincidimos con Barash que, en estas obras tardías, el concepto símbolo pierde gran parte de la presencia que supo tener en "Ideología y Utopía, Freud. Una interpretación de la cultura", o incluso, "La simbólica del mal". Esto no significa, sin embargo, que esta categoría haya desaparecido. Como esperamos mostrar en los próximos párrafos, somos de la idea de que este concepto fue más bien desplazándose a un segundo plano a medida que Ricoeur fue adentrándose distintas mediaciones de la realidad, como es el caso de la metáfora o de la narración. Por otra parte, tampoco coincidimos con su afirmación de que ha habido una desaparición absoluta de este concepto en sus últimas obras. En lo referente a "La memoria, la historia, el olvido", Ricoeur recurre al 'símbolo' en múltiples oportunidades. Sin embargo, ha sido justamente en respuesta a esta observación de Barash que nos hemos topado con el límite absoluto a la resolución de las aporías del tiempo. Para su tratamiento, nos restringiremos a dos momentos de "La memoria, la historia, el olvido" en particular: el primero que se encuentra en el capítulo dedicado a "Los abusos de la memoria natural", fundamentalmente la sección dedicada a la memoria manipulada, y el segundo en el capítulo sobre "La muerte en historia".

Ricoeur toma al cumplimiento de la capacidad mnémica, es decir, al reconocimiento, como la base para su análisis de la memoria: "A mi modo de ver, lo que importa es abordar la descripción de los fenómenos mnemónicos desde 
el punto de vista de las capacidades de las que ellos constituyen la efectuación 'feliz'." (Ricoeur, 2004a, p. 40). Esta capacidad consta de dos componentes, uno pasivo y otro activo. El primero está ligado con las huellas mnémicas, y su antecedente histórico se puede retrotraer hasta el recuerdo puro de Henry Bergson. El componente activo, por su parte, consiste en la materialización o efectivización imaginativa del recuerdo. El reconocimiento no es otra cosa que la exitosa fusión de estos dos momentos que dan la sensación de "ya visto". ${ }^{10} \mathrm{El}$ capítulo "La memoria ejercida: uso y abuso" describe los efectos mnémicos de la disfunción de cada uno de estos momentos. En un extremo, los abusos de la memoria artificial nos presentan los excesos a los que llevan los ejercicios de la memorización. En ellos, la pasividad de la impronta, originada por haber sido afectado por un acontecimiento en el pasado, acaba siendo desplazada totalmente por la actividad de la imaginación. ${ }^{11}$ En el otro extremo se encuentra la memoria traumatizada, una pura pasividad que no es configurada en lo absoluto. En medio de ambas se encuentra la manipulación mnémica en la que intervienen ambos componentes: la memoria es instrumentalizada por terceros, lo que afecta al componente pasivo, pero también posee una intervención activa de quien es afectado debido a la complicidad con quien lo manipula.

En ningún lugar de las secciones dedicadas a la memoria impedida y a la manipulada, Ricoeur aclara cuál de los sentidos de símbolo arriba mencionados preferirá o si utilizará ambos. Consideramos, empero, que el recurso al antropólogo Clifford Geertz para explicar la mediación simbólica en el nivel más profundo de la ideología, nos proporciona una indicación de que Ricoeur utilizará el sentido amplio del símbolo. Recordemos que en "Tiempo y narración", tras haber señalado su preferencia por el sentido amplio del símbolo, por aplicarse a todos los procesos culturales que articulan la totalidad de la experiencia, ${ }^{12}$ Ricoeur recurre a los aportes conceptuales de Geertz para explicar en qué consiste la mediación simbólica. Este nexo con “Tiempo y narración” nos llevará a que tomemos a esta sección como punto de inicio de nuestro tratamiento del símbolo.

En esta sección, Ricoeur plantea la necesidad de articular sus antiguos análisis sobre la ideología, con los más recientes en torno a la identidad narrativa y la memoria, a fin de buscar determinar la incidencia de la narración legitimante del poder en la identidad tanto colectiva como individual. Independientemente del desarrollo intelectual del filósofo, hay una primera dificultad en esta articulación de carácter nominal consistente en la modificación del primero de los niveles 
de la ideología. Recordemos que en "Ideología y Utopía" los niveles eran denominados "identificación, legitimación y distorsión", ${ }^{13}$ mientras que en "La memoria, la historia, el olvido", el primero de los niveles pasa a denominarse "integración del mundo común". ${ }^{14}$ La segunda dificultad es que la ideología es presentada como un fenómeno intercalado en la relación entre la fragilidad de la memoria y la identidad. ${ }^{15}$ La dificultad estriba aquí en que la ideología no es un elemento extraño, que simplemente se lo debe agregar, sino que es constitutiva a la narración identitaria misma, por lo que su articulación es bastante más compleja. Lo que nos lleva a la última dificultad y es que Ricoeur sólo presenta el nexo entre ambas pero no lo lleva a cabo. Aún siendo conscientes de que ambas obras remiten a momentos diferentes del autor, seguidamente propondremos una posible articulación, tomando como eje las preocupaciones de "La memoria, la historia, el olvido", no sólo para destacar la presencia de lo simbólico en ella, sino también para identificar aquellas instancias en la que Ricoeur desdibuja la diferencia con la memoria herida.

El occidente ha recurrido a la memoria como criterio de identidad, y uno de los aspectos centrales del análisis de Ricoeur ha sido poner de manifiesto la incidencia de la imaginación en coadyuvando a la memoria, en la síntesis mnémica y plenificando al recuerdo puro, pero con el constante peligro de adulterar a esta capacidad. ${ }^{16}$ Ahora bien, en el centro de la concepción ricoeuriana de la memoria ya no nos encontramos con una facultad psico-fisiológica que registra pasivamente lo vivido, sino con una función narrativa de recolección y preservación de lo acontecido que reconocemos como propio. ${ }^{17} \mathrm{La}$ identidad narrativa, tanto personal como colectiva, es equiparable con la identidad de un personaje de una trama. ${ }^{18}$ Este tipo de identidad es constitutivamente inestable, afectable no sólo por el paso del tiempo, sino también por la amenaza del otro y la herencia de la violencia fundadora.

13 Cf. Ricoeur 1986, p. 310.

14 Cf. Ricoeur 2004a, p. 112.

15 Cf. Ricoeur 2004a, p. 111: "Las manipulaciones de la memoria que evocaremos más tarde se deben a la intervención de un factor inquietante y multiforme que se intercala entre la reivindicación de identidad y las expresiones públicas de memoria. Se trata del fenómeno de la ideología, cuyo mecanismo intenté desmotar en otro lugar."

16 Excedería el alcance de este trabajo detenernos en la relación entre memoria e imaginación. Para ello, consultad Amalric (2012), Kearney (1998), Taylor (2006) y Lythgoe (2014).

17 Cf. Ricoeur, 1995b, p. 6: "But to speak of memory is not only to evoke a psycho-physiological faculty which has something to do with the preservation and recollection of traces of the past; it is to put forward the 'narrative' function through which this primary capacity of preservation and recollection is exercised at the public level of language."

18 Cf. Ricoeur 1996b, p. 139: "la identidad, entendida narrativamente, puede llamarse, por convención de lenguaje, identidad del personaje." 
La asociación de la identidad narrativa con la memoria permite que Ricoeur se retrotraiga a sus análisis sobre el nivel más profundo de la ideología, elaborados por Geertz. Esta remisión es explicada en los siguientes términos, "en el plano más profundo [de la ideología], el de las mediaciones simbólicas de la acción, la memoria es incorporada a la constitución de la identidad a través de la función narrativa." (Ricoeur, 2004a, p. 115). Esta remisión no es caprichosa, pues estaba presente ya en "Ideología y Utopía”, donde Ricoeur sostenía que "esta memoria permanente de los fundadores del grupo o de los acontecimientos fundacionales es, luego, una estructura ideológica que puede funcionar positivamente como una estructura integradora" (Ricoeur, 1986, p. 261).

La asociación entre identidad e ideología mediada por lo simbólico, surge de la concepción de Geertz de la ideología. Este antropólogo interpretaba a la ideología por medio de instrumentos de la semiótica. En su opinión, toda acción social se encuentra mediada simbólicamente, por lo que resulta imposible una integración social sólo con lo que nos aporta la biología humana. Requerimos de los símbolos para que al integrarnos socialmente, nos aporte una identidad. Ricoeur también recurre a este antropólogo para poner de manifiesto el estrecho nexo entre ideología y política, nexo que le permite articular este primer sentido de ideología como mediación simbólica con la ideología en el sentido weberiano de legitimación. Es así que este análisis de "Ideología y utopía" posibilita la articulación entre estos dos sentidos de ideología y proporciona asimismo una justificación al sentido marxiano de la ideología en tanto distorsión. Ricoeur explica esta mutua remisión en los siguientes términos:

La noción de lo autoritario es un concepto nuclear, porque cuando el problema de la integración conduce al problema de un sistema de autoridad, el tercer concepto de ideología nos reconduce al segundo. No es por azar que existe un lugar específico para la ideología en política, porque la política es el lugar donde las imágenes básicas de un grupo proveen finalmente reglas para el uso del poder. Las cuestiones de la integración conducen a las preguntas de legitimación, y éstas a su vez llevan a las cuestiones de la distorsión (Ricoeur, 1986, p. 259).

Estas consideraciones de Ideología y utopía le aportan a Ricoeur los elementos necesarios para explicar en La memoria, la historia, el olvido de qué manera los poderosos recurren a retóricos a fin de legitimar y justificar su poder (segundo nivel de ideología), ${ }^{19}$ aún distorsionando lo sucedido a través del desplazamiento del interés de ciertos momentos del pasado o lo supriman directamente (tercer nivel), de manera tal que sus gobernados se 
sientan amenazados por la desintegración social (primer nivel de ideología) (Ricoeur, 2004a, pp. 572-576).

Tras una primera lectura de esta sección, uno tiene la impresión de que está dedicada a poner de manifiesto de qué manera quienes tienen el poder, manipulan la memoria colectiva de sus subordinados a través de la ideología. Sus subordinados, incapaces de defenderse, son afectados pasivamente en su identidad, tanto individual como colectiva. Aunque hay varias citas que avalan esta interpretación, ella es errónea, pues el énfasis del abuso de los poderosos por sobre los demás actores sociales, exacerba la manipulación, conduciendo a una equiparación la memoria manipulada con la impedida. Como lo adelantamos al introducir esta temática, la instrumentalización mnémica por parte del poder es complementada por una aceptación activa por parte de quienes son manipulados. Por una parte, uno sólo se identifica con una narrativa realizada por terceros, en este caso los retóricos, ésta debe ser reconocida y asumida como propia. A esta necesidad de reconocimiento, se le agrega un segundo componente asociado con la semiactividad de los subordinados, relacionado con el desinterés es indagar sobre el pasado. En la sección dedicada a El olvido y la memoria manipulada, Ricoeur caracteriza la complicidad de los subordinados de la siguiente manera:

Pero este desposeimiento va acompañado de una complicidad secreta, que hace del olvido un comportamiento semipasivo y semiactivo, como sucede en el olvido de elusión, expresión de mala fe, y su estrategia de evasión y esquivez motivada por la oscura voluntad de no informarse, de no investigar sobre el mal cometido por el entorno del ciudadano, en una palabra, por un querer-no-saber (Ricoeur, 2004a, p. 572).

Además de la crítica a las ideologías, Ricoeur menciona el recurso al psicoanálisis como vía para resolver la distorsión producida por la ideología, lo cual desdibuja aún más las diferencias existentes entre la memoria manipulada y la herida, En la sección "El olvido y la memoria manipulada" hay una extensa remisión al "Síndrome de Vichy", obra de Henry Rousso, donde se abordan con categorías psicoanalíticas los comportamientos públicos y privados que se dieron desde 1940 hasta la actualidad con respecto a ese período de la historia francesa. Incluso hay otros textos previos a "La memoria, la historia, el olvido" donde Ricoeur asocia al psicoanálisis y a la historia con diversos problemas de identidad narrativa. Así, "Tiempo y narración III", tras presentar a la identidad narrativa y su aplicabilidad a nivel individual y comunitario, Ricoeur propone que el psicoanálisis puede servir como 'laboratorio' para indagar el alcance de este concepto, así como el rol que cumple la narración. En el proceso de perlaboración, explica, el analista sustituye "[...] los fragmentos de historias, a la vez, ininteligibles e insoportables, por una historia coherente y aceptable, 
en la que el analizador pueda reconocer su ipseidad" (Ricoeur, 1996a, p. 999). De manera análoga, la historia "[...] procede de la serie de correcciones que cada nuevo historiador aporta a las descripciones y a las explicaciones de sus predecesores, $\mathrm{y}$, progresivamente, a las leyendas que han precedido este trabajo propiamente historiográfico" (Ricoeur, 1996a, p. 999). Sin embargo, Ricoeur reconoce que hay un límite para la aplicación de las categorías de la psicopatología de la vida cotidiana, así como también las de la sociología de la ideología, que se encuentra "en la parte intransmisible de la experiencia extrema” (Ricoeur, 2004a, p. 577). Es acerca de esta parte que está dedicada la memoria herida.

La sección acerca de la memoria herida consta de dos partes, en la primera Ricoeur articula dos textos de la metapsicología freudiana: Duelo y melancolía y Rememoriación, repetición, per-laboración. El objetivo de esta parte es contraponer el trabajo (del recuerdo) a la compulsión (de la repetición) y asociar el trabajo del recuerdo con el duelo. En la segunda parte, Ricoeur argumentará a favor de la traslación directa de la metapsicología del individuo al colectivo. En principio, esta sección debería tematizar a la memoria incapaz, completamente pasiva, así como también proporcionar las herramientas, volverla capaz, incorporándole el elemento activo y posibilitando así el trabajo de rememoración. Resulta curioso, empero, que, aunque una de las preguntas inaugurales de la sección sea acerca de su tratamiento, ${ }^{20}$ Ricoeur no se detenga en ningún momento a explicar en qué consiste la patología de la memoria. Consideramos, sin embargo, que es posible reconstruir en qué consistiría "la parte intransmisible de la experiencia extrema" a partir de los planteos de Barash acerca del símbolo.

A diferencia de la sección sobre la memoria manipulada, en ésta sólo se menciona al símbolo esporádicamente, y ninguna de estas menciones tiene un rol de relevancia en la argumentación..$^{21}$ A nuestro parecer, esta ausencia es

20 Cf. Ricoeur 2004a, p. 97:“[...] en qué medida la patología de la memoria, en consecuencia, el tratamiento de la memoria como pathos, se inscribe en una investigación sobre el ejercicio de la memoria, sobre la tekhné memorial."

21 En esta sección, hay cinco referencias, que a su vez se pueden reunir en tres tipos de menciones diferentes: Las primeras dos se encuentran en un raconto histórico que hace Ricoeur sobre el abordaje histórico que se hace de la melancolía. Describiendo el grabado de Durero Melancolía I, Ricoeur lo describe del siguiente modo: "Una mujer está sentada: su mirada, fija en la distancia vacía; su rostro, sombrío; el mentón, apoyado en un puño cerrado; de su cinturón cuelgan unas llaves símbolo de poder, y un monedero, símbolo de riqueza; en suma, dos títulos de vanidad (Ricoeur, 2004a, p. 104). El segundo grupo se encuentra en lo que Ricoeur describe como una 'justificación provisional' para aplicar las categorías psicoanalíticas a lo colectivo: "La traslación se hizo más fácil por ciertas reinterpretaciones del psicoanálisis próximas a la hermenéutica, como se ve en algunos trabajos antiguos de Habermas, en los que el psicoanálisis es reformulado en términos de desimbolización y de re-simbolización, y en los que se recalca la función de las distorsiones sistemáticas de la comunicación en el plano de las ciencias sociales" (Ricoeur, 2004a, p. 107). Finalmente, haciendo referencia 
significativa, no sólo por la importancia que tuvo este concepto en la obra de Freud, sino también por el papel recién descripto del psicólogo y del historiador como una suerte de canalizadores simbólicos. Consideramos que la pista de los motivos de esta ausencia, así como las consecuencias de su falta nos la aporta un artículo que Ricoeur escribe en 1988: "La narración: su lugar en el psicoanálisis". En este, se pone de manifiesto la correlación existente entre las psicopatologías, la dimensión simbólica y el tiempo. En términos generales, las patologías psíquicas son caracterizadas como una descomposición de la función simbólica, como el producto de la denarrativización del deseo. ${ }^{22}$ Los síntomas son fragmentos de narraciones no coordinables en un relato coherente. En la medida en que la narración configura el tiempo, la descomposición simbólica sustrae al ser humano del tiempo. En efecto, "la comprensión que tenemos de nosotros mismos es una comprensión narrativa, es decir, que no podemos aprehendernos a nosotros mismos fuera del tiempo y, por lo tanto, fuera de la narración [...]" (Ricoeur, 2008, p. 277, Énfasis mío). Aunque en La memoria, la historia, el olvido, Ricoeur no plantea explícitamente esta triple correlación, sí se detiene en los efectos temporales que tienen las patologías mnémicas (Ricoeur, 2004a, p. 570-571). La compulsión a la repetición rompe "los hilos del presente con el pasado", conduciendo al olvido, aun cuando persistan las huellas mnémicas. En estos casos, el recuerdo es indisponible porque está sustraído del tiempo, porque el tiempo no se ha vuelto humano, esto quiere decir, según el artículo de 1988 que no se encuentra "simbolizado".

Sin embargo, en el capítulo de la memoria herida no se hace tanto énfasis en esta carencia de lo simbólico. Por el contrario, como señalamos al referirnos a la memoria manipulada, encontramos otros elementos que desdibujan las diferencias entre ambos tipos de abusos mnémicos. Lo paradójico de este solapamiento es que mientras en la memoria manipulada se destaca la pasividad de los súbditos manipulados, en la memoria herida se destaca la actividad de la memoria impedida, como se pone de manifiesto cuando Ricoeur señala la necesidad de la activa cooperación del analizado con el analista. El que haya intérpretes que superpongan ambos tipos de abusos mnémicos, refuerza nuestra posición de que, desde un punto de vista argumentativo, de que en "La

a la violencia fundadora, que se queda asociada con la memoria manipulada explica: "Así se almacenaron en los archivos de la memoria colectiva heridas simbólicas que exigen curación" (Ricoeur, 2004, p. 211). En todos los casos, la cursiva en el término 'símbolo' es nuestra.

22 En este punto es clara la correlación entre lo simbólico y la narración señalada más arriba. Consultad Ricoeur, 2008, p. 285: "Dans la constitution de la maladie, parce que ce que nous avons appelé «désymbolisation» est aussi une «dénarrativisation», c'est-à-dire que le patient n'est pas capable de constituer un récit intelligible et acceptable de sa propre vie." 
memoria, la historia, el olvido" se desdibuja la distinción nominal planteada entre distintos abusos mnémicos. Este es el caso, por ejemplo, de Rudolf Boutet, quien reúne la ideología, asociada en estas páginas con la memoria manipulada, con la compulsión a la repetición, propia de la memoria impedida, con estos términos: "Pero es también en virtud de otro caso de figura, la de la tendencia ideológica a la conmemoración, que el empleo ricoeuriano de la compulsión a la repetición adquiere su plena legitimidad conceptual" (Boutet, 2016, p. 155).

En nuestra opinión, tanto el solapamiento entre ambos tipos de abusos mnémicos como la similitud en su tratamiento están asociados a las obras metapsicológicas que Ricoeur utiliza como fundamento para el análisis de la memoria impedida y el modo en que las articula entre sí. En "Duelo y melancolía”, Freud explica que la melancolía es una patología psíquica en la que el sentimiento de sí se ve reducido debido a la pérdida de un objeto amado. El duelo, en cambio, es presentado fundamentalmente como contrafigura de la melancolía, cuyo trabajo permite desligarse del objeto perdido y recuperar el sentimiento de sí. A la base del pasaje de la melancolía al duelo se encuentra la tensión entre la libido, que nos vincula al objeto amado, y el principio de realidad, que nos enfrenta a la desaparición de dicho objeto. Freud destaca que el trabajo para que la libido obedezca a la realidad requiere una gran cantidad de tiempo y energía. Por su parte, "Rememoración, repetición, per-laboración" destaca el componente activo y procesual en todas las instancias. Con otras palabras, destaca el concepto de trabajo presente, fundamentalmente en la rememoración. Así, mientras "Duelo y melancolía" proporciona las categorías necesarias para comprender las patologías psíquicas, "Rememoración, repetición, per-laboración" elabora las capacidades del ser humano. Ricoeur considera que no es casual que el duelo y la rememoración coincidan en ser concebidos como un trabajo. En su opinión,

Lo que hace del duelo un fenómeno normal, aunque doloroso, es que 'una vez terminado el trabajo de duelo, el yo se halla de nuevo libre y deshinbido.' Es en este aspecto como el trabajo de duelo puede relacionarse con el trabajo del recuerdo. Si el trabajo de la melancolía ocupa en el presente ensayo una posición estratégica paralela a la que ocupa la compulsión de repetición en el precedente, se puede sugerir que el trabajo de duelo se revela costosamente liberador como trabajo del recuerdo, pero también recíprocamente (Ricoeur, 2004a, p. 100).

Al tratar al duelo y a la rememoración como dos caras de la misma moneda, desaparece la posibilidad de tratar un proceso de duelo de manera cualitativamente diferente a una manipulación mnémica. Aún en aquellas situaciones extremas señaladas más arriba, la noción misma de trabajo "[...] supone que los trastornos en cuestión no son sólo sufridos, sino que también somos responsables de ellos, 
como lo atestiguan los consejos terapéuticos que acompañan la per-laboración" (Ricoeur, 2004a, p. 109).

Somos de la idea de que en el marco de La memoria, la historia y el olvido, existen elementos suficientes para reconstruir otra función diferente al psicoanálisis y la historia, que la de re hilvanar narraciones manipuladas, para afrontar situaciones aún más extremas, como las presentadas en "La narración: su lugar en el psicoanálisis". Para recoger aquellos elementos del duelo, ligados con la resimbolización, que fueron dejados de lado en el tratamiento de la memoria herida, es preciso remitirnos a la recepción que hace Ricoeur de las tesis de Michel de Certeau acerca de la muerte y la historia en la parte dedicada a 'La condición histórica'. A diferencia de "Tiempo y narración”, donde Ricoeur rechazaba el excesivo énfasis que De Certeau le asignaba a la muerte frente a la vida (Ricoeur, 1996a, p. 863, nota); en "La memoria, la historia el olvido", el filósofo toma conciencia de su relevancia filosófica en su carácter de 'relato fundador' (Ricoeur 2004a, p. 475). Antes que un nuevo objeto de la historia, la muerte es la condición de su posibilidad, que constituye al pasado como tal y articula la relación entre los lectores presentes y los muertos pasados. En efecto, según De Certeau, el asiento escritural de los muertos cumple una doble función. La primera es etnológica y cuasi religiosa, donde "[...] la escritura desempeña el papel de un rito de entierro, ella exorciza a la muerte introduciéndola en el discurso." (De Certeau, 2006, p. 116). Escribir historia se convierte en el equivalente del rito de la sepultura, pasando de la sepultura-lugar a la sepultura-gesto. De Certeau explica que con este acto el historiador honra y elimina al muerto: “[...] la reconducción del 'muerto' o del pasado a un lugar simbólico se articula aquí con el trabajo que tiene por fin crear en el presente un lugar (pasado o futuro) que debe llenarse, un 'deber' que hay que cumplir. La escritura recoge el producto de este trabajo; de esta manera libera al presente sin tener que nombrarlo" (De Certeau, 2006, p. 117). Ricoeur intercala en este punto del planteo de De Certeau al duelo, y afirma: "la sepultura como lugar material se convierte así en la señal duradera del duelo, el memorándum del gesto de sepultura" (Ricoeur, 2004a, p. 472). Articulando estas consideraciones, con aquellas ligadas con la memoria herida, es posible sostener que, así como el duelo liberaba a la libido del vínculo con el objeto perdido (Ricoeur, 2004a, p. 100), lo mismo posibilita el gesto de sepultura del historiador al presente.

De Certeau asigna una segunda función a la escritura historiográfica, de carácter performativo, que sugestivamente es denominada 'simbolizadora', que permite articular los distintos tiempos que habían quedado desarticulados. Según explica el historiador, 
[esta función] permite a una sociedad situarse en un lugar al darse en el lenguaje un pasado, abriendo así al presente un espacio: 'marcar' un pasado es darle un lugar al muerto, pero también redistribuir el espacio de los posibles, determinar negativamente lo que queda por hacer, y por consiguiente utilizar la narratividad que entierra a los muertos como medio de fijar un lugar a los vivos (De Certeau, 2006, pp. 116-117).

Ricoeur emparenta esta función con el proceso de duelo, diciendo que, "el trabajo de duelo separa definitivamente el pasado del presente y da paso al futuro" (Ricoeur, 2004a, p. 639). En su artículo "La marca del pasado", escrito unos años antes de "La memoria, la historia, el olvido", Ricoeur reconoce un cambio en su concepción de la tensión aporética entre el tiempo cosmológico y el tiempo vivido respecto a cómo la había presentado en "Tiempo y narración". Así explica:

esta dificultad [la falla entre ambos tiempos] perdió su agudeza en la presente obra, en la medida en que, yendo contra San Agustín, e incluso Heidegger, el tiempo fenomenológico me parece comportar, de manera primordial, rasgos tales como la fechabilidad, por los cuales el tiempo del mundo es incorporado a la escansión del tiempo fenomenológico mismo (Ricoeur, 1999, p. 167, nota).

Consideramos que esta incorporación de la fechabilidad en el tiempo fenomenológico está directamente asociada al reconocimiento de la función simbolizadora de la historia descrita por De Certeau. Recordemos los tres rasgos comunes de los calendarios, según Ricoeur: 1. Determinación de un momento axial a partir del cual son datados todos los acontecimientos; 2. Con relación a este eje, la posibilidad de recorrer el tiempo en dos direcciones, desde el presente al pasado, y del pasado al presente; 3. Proporcionar un repertorio de unidades de medidas. ${ }^{23}$ Hemos visto que el entierro escritural 'marca' el pasado, es decir, lo constituye en un eje, a partir del cual uno lee desde el presente el pasado, y llega del pasado al presente. Las conmemoraciones y aniversarios posteriores se realizarán en base a este eje. Con otras palabras, lo que "La marca del pasado" describe como la incorporación del tiempo del mundo al tiempo fenomenológica a través de la fechabilidad, no es sino el proceso de duelo social iniciado en el proceso de escritura de la historia.

En síntesis, en la medida en que la condición de posibilidad de rememorar es la capacidad de narrar y articular los distintos momentos temporales, consideramos que el vínculo de la función simbolizadora con el duelo, supone que este proceso cumple una función aún más fundamental que el trabajo de rememoración. Por 
lo tanto, no puede ser identificada con el trabajo de rememoración con el trabajo de duelo, sino que debe reconocérsele esta función adicional.

\section{Acerca de la imposibilidad de un límite extra-simbólico}

Hemos comenzado este análisis con la correlación planteada por Ricoeur entre tiempo y narración. Según explicaba en aquella obra, "de modo esquemático, nuestra hipótesis de trabajo quiere considerar la narración como el guardián del tiempo en la medida en que no existiría tiempo pensado si no fuera narrado" (Ricoeur, 1996a, p. 991). Allí postulamos que, junto con los límites internos y externos que la propia narrativa presentaba a la hipótesis de Ricoeur, había un límite no explorado en "Tiempo y narración", pero cuyos lineamientos podían ser rastreados en "La memoria, la historia, el olvido". Nos referimos a aquel en el que no hay narración y, por lo tanto, tampoco tiempo, aunque consideramos que no era aplicable a la narración histórica, sino a la memoria impedida. Apoyándonos en el concepto de 'símbolo', observamos el contraste que existía entre las referencias existentes de este concepto en la sección dedicada a la memoria manipulada, y su casi absoluta ausencia en el tratamiento de la memoria impedida. Dado que esta ausencia estaba asociada con lo no temporal y con la experiencia extrema, consideramos que esta ausencia no debía considerarse, como propone Barash, como un abandono de la temática del símbolo por parte de Ricoeur, sino a que nos encontramos con un límite sui generis de la función simbólica.

Nos resultó paradójico, con todo, a que pese a las diferencias conceptuales de base entre la memoria manipulada y la memoria impedida, en el desarrollo de cada una de las secciones se introdujeran diversos elementos que desdibujaron esta distinción. Señalamos algunas frases que enfatizaban la pasividad de los subordinados frente a la manipulación ideológica y la presencia de categorías psicoanalíticas, en lo referente a la memoria manipulada. Más llamativo aún resultó la constante presencia de la actividad del trabajo en la memoria impedida, porque atentaba con la tesis ricoeuriana de la pasividad de la memoria herida. Este hecho contrastaba con un artículo previo de Ricoeur, "La narración: su lugar en el psicoanálisis", donde señalaba patologías mnémicas asociadas a experiencias límites como las señaladas en "La memoria, la historia, el olvido" que conducían a un proceso de desnarrativización o desimbolización, con la consecuente ruptura del entramado temporal. Incluso se enfrentaba con la valoración que en "La memoria, la historia, el olvido" se hace de Michel de Certeau, y el reconocimiento de la función simbolizadora de la escritura de la historia, que permite reestablecer el entramado temporal. 
Más allá de haber presentado este proceso de resimbolización presente ligado al gesto certeano de la sepultura simbólica del pasado en la escritura de la historia, seguimos sin entender los motivos por los que Ricoeur, pese a haber vislumbrado esta posibilidad de una memoria incapaz, no logró proporcionar categorías para tematizar esta situación, pese a ser una situación excepcional. Una posibilidad cuyo estudio deberá ser abordado con posterioridad es que Ricoeur haya considerado inconcebible la no narración como límite de la refiguración del tiempo. Al fin y al cabo, "entre la actividad de narrar una historia y el carácter temporal de la existencia humana existe una correlación que no es puramente accidental, sino que presenta la forma de necesidad transcultural" (Ricoeur, 1995a, p. 113).

\section{Referencias}

AMALRIC, J-L. "L'Imagination poetico-pratique dans l'identité narrative". Études Ricoeuriennes / Ricoeur Studies, Vol. 3, Nr. 2, pp. 110-127, 2012.

BARASH, J. A. "Collective Memory \& the Historical Past". Chicago \& London: The University of Chicago Press, 2017.

BOUTET, R. "Temps et psychanalyse chez Ricoeur. Confrontation de deux perspectives sur le passé". Études Ricoeuriennes / Ricoeur Studies, Vol. 7, Nr. 1, pp. 148-165, 2016. DE CERTEAU, M. "La escritura de la historia". México: Universidad Iberoamericana, 2006.

FRIEDLANDER, S. (comp.) "En torno a los límites de la representación. El nazismo y la solución final". Bernal: Universidad Nacional de Quilmes, 2007.

GREISCH, J. "Paul Ricoeur, l'itinérance du sens". Grenoble: Jérôrme Millon, 2001. LEVI, P. "Los hundidos y los salvados". Barcelona: Muchnik, 1989.

LYTHGOE, E. "Social imagination, abused memory, and the political place of history in Memory, History, Forgetting". Études Ricoeuriennes / Ricoeur Studies, Vol. 5, Nr. 2, pp. 35-47, 2014.

KEARNEY, R. "Poetics of Imagining: Modern to Post-Modern". Edinburgh: Edinburgh University Press, 1998.

RICOEUR, P. "Lectures on Ideology and Utopia". New York: Columbia University Press, 1986.

. "Freud: una interpretación de la cultura". México: Siglo XXI, 1990. "Tiempo y narración I. Configuración del tiempo en el relato histórico".

México-Buenos Aires: Siglo XXI, 1995a.

. "Reflections on a new ethos for Europe". Philosophy and Social Criticism, v. 21, n. 5/6, 1995b, pp. 3-13.

. "Tiempo y narración III". Buenos Aires: Siglo XXI, 1996a.

"Sí mismo como otro". Buenos Aires: Siglo XXI, 1996 b.

"La marca del pasado". Historia y Grafía, Nr. 13, pp. 157-185, 1999. 
. "La memoria, la historia, el olvido". Buenos Aires: Siglo XXI, 2004a.

. "Finitud y culpabilidad". Madrid: Trotta, 2004b.

. "Écrits et conférences 1. Autour de la psychanalyse" Paris: Seuil, 2008.

TAYLOR, G. "Ricœur's Philosophy of Imagination". Journal of French Philosophy, Nr. 16, pp. 1-2, 2006.

VERGARA ANDERSON, L. "La producción textual del pasado I: Paul Ricoeur y su teoría de la historia anterior a La memoria, la historia, el olvido". México: Universidad Iberoamericana, 2004. 